\title{
How the Turn to Practice may contribute to Working Life Studies
}

I Silvia Gherardi'

Professor, University of Trento, Italy, and Aalto University, Finland

\begin{abstract}
Working life studies and practice-based studies have a common interest for work, and how work is accomplished in situated working conditions. The turn to practice may contribute to renew the study of work. The main concern of a practice-based approach to working practices is to understand the logic of the situation and the performance of action as practical knowledge, which connects working with organizing and knowing with practicing. The article will first illustrate the basic assumptions of an approach to working practices based on a post-humanist practice theory and second it will focus on a specific contribution from it. I shall argue that a practice approach to innovation as a continuous process contributes to a better understanding of how working practices change or persist. In fact, the study of work in situation is not only descriptive in its purpose, but it is also intended to yield practical outcomes for empowering practitioners in their attachment to practicing.
\end{abstract}

\section{KEY WORDS}

Attachment / aesthetic knowledge / innovation / practice / post-humanism

DOI

10.19154/njwls.v5i3a.4831

\section{Introduction}

(T)

orking life studies is a very broad field with many approaches and epistemologies for studying the relationship of life at work and life outside it. It has a long tradition of excellence, especially in the Nordic countries; on the contrary, practice-based studies have gained visibility especially from 2000 onwards and have not yet consolidated a dialog with working life studies. There is a difficulty in tracing the boundaries of 'working life studies' in contemporary debate and within academic communities more or less oriented to work science, and for this reason, I do not dare to open the black box of such an inclusive definition, rather I wish to take the opportunity of the present special issue for reflecting on the potential contribution that the turn to practice may offer to research on work.

The main concern of a practice-based approach to working practices is to understand the logic of the situation and the performance of action as practical knowledge, which connects working with organizing and knowing with practicing. It assumes the term 'practice' as epistemology, following the shift from knowledge to knowing - and

\footnotetext{
${ }^{1}$ Silvia Gherardi, Dipartimento di Sociologia e Ricerca Sociale, Via Verdi 26, 38122 Trento, Italy, E-mail: silvia.gherardi@unitn.it
} 
therefore from an epistemology of possession of knowledge (Cook \& Brown, 1999) to one of practice - that is, to a conception of knowing as a practical, collective activity, and an activity entangling matter with meaning. It views actions as 'taking place' or 'happening', as being performed through a network of connections-in-action, as lifeworld and dwelling in practices.

The sociology of practice (Gherardi, 2011) furnishes a theory of knowledge that re-frames all material-discursive elements as practice phenomena, interpreting them in terms of a collective, situated, and knowledgeable doing. Working practices are the sites where knowing how to go on and how to innovate the way of doing are produced, diffused, and kept. Therefore to understand how practical knowledge about work is 'done' in situated circumstances and by knowledgeable practitioners may contribute to the field of working life studies in empowering practitioners through a collective reflection on practice innovation. Moreover, as neoliberalism is changing the political and economic context that favored the rise of working life studies in the Nordic countries, a practicebased approach to innovation in working practices may contribute to a renewal of these studies.

The present article will present one way of approaching practice-based studies based on a post-humanist practice theory and it will illustrate the main assumptions behind it. Once a theoretical and methodological framework to approaching working practices will be outlined, the topic of innovation as a continuous process and as a process of refinement of practices will be introduced. The main argument of the paper is in fact that one of the contributions of practice-based studies to inquiries on working life is a reflection on how practices may change 'from within' and why they may persist.

\section{The main assumption of a post-humanist practice theory}

Practice theories have a long theoretical history, and they draw on a wide range of methods, in philosophy, in social sciences, and in sociology in particular. Nevertheless, there has been a 'return' of interest in the concept of practice (Miettinen et al., 2009), around 2000, and especially within the studies on learning and knowing as situated activities in working practices. After a first moment in which the first generation of practice theorists have been revisited - in sociology Garfinkel, Bourdieu, Giddens - the time has come to start anew with examination of the concept which draws on more recent practice theories.

In a special issue (Eikeland \& Nicolini, 2011) devoted to broadening the horizon and turning practically, the editors, after sketching a classification of practice studies according to their definition of practice (from outside and above vs. from within and below) and the direction of interest (broadly practical vs. broadly theoretical), claim that the practice turn is still incomplete. Therefore, their linguistic game in substituting 'turning practically' to 'practice turn' has an important message. Their focus is on the practices of the knower. In their conception, turning to practice does not mean becoming more engaged, or making social science more relevant to the practical concerns of practitioners; rather, it means developing a type of theory (called theoria) that is about proceeding from within an activity, making its "grammar" explicit, opening new possibilities for action, and informing mindful, caring, and wise conduct' (Eikeland \& Nicolini, 2011, p. 9). 
A tension between a 'practice turn' and a 'turn to practice' is depicted as centring on the issue of a critical and emancipatory role for knowledge production. Nevertheless, other tensions (between disciplinary backgrounds and between epistemologies) are shaking the field and producing differences at a deeper level. In my opinion, a main difference, if not a tension, is between a theory of practice in the humanist paradigm (i.e., centered on the subject and his/her practices, from which meaningful action proceeds) and a post-humanist one.

Posthumanism has accompanied a rethinking of science, technology, and causality, shifting focus from epistemology of human consciousness to 'quantum ontology' of matter and time-space (Clough, 2009, p. 47). Sociality with objects, sociomateriality, relational materialism, and similar concepts are employed for enabling a conversation around 'practice' as the site where humans and nonhumans are entangled. I shall keep the term nonhuman, assuming that it also covers the nuances of other terms like other-then-humans (Langley \& Tsoukas, 2010), or more-than-human (Braidotti, 2013; Edwards \& Fenwick, 2014).

Actor-network theory and Latour (2005) have paved the way for the elaboration of a theoretical sensibility in which practice is seen as an epistemology and not only an empirical object.

In the following sections, I shall outline the basic assumptions for analyzing practices within a post-human practice theory.

\section{A practice is more than an array of activities}

Going to the cinema is an example of a social practice familiar to us and which we perform with greater or lesser frequency. Let us use Garfinkel's (1967) technique to defamiliarize this practice by asking ourselves: when does the practice 'going to the cinema' begin? When we enter the cinema, when we buy the ticket, when we arrange with our best friend to go and see the film? And does it finish with watching the film? Or, part of the practice 'going to the cinema' is also talking about the film afterwards over a beer, or sometime later with a group of friends? The pleasure of going to the cinema continues and is renewed through discussion of films that we have seen. Going to the cinema is therefore connected with other sociability practices that form the texture of 'being together' and link with identity practices to show others that we are 'abreast with the facts of the world'.

The point that I wish to make is that a practice is much more than a set of activities. It does not consist solely in the motive that generated it or the goal that it pursues. Performing a practice activates numerous dimensions besides the instrumental one, so that functional analysis alone of practice may be useful but is reductive.

Saying that practices are not simply sums of activities, but ways of doing things, and that they are socially supported, directs attention to the social processes that maintain practices 'alive' and therefore reproduce them dynamically. This means that a practice is a constantly disputed terrain and is supported both by forms of sharing and harmony and by forms of dissent and conflict. In fact, being an 'expert' practitioner gives entitlement (legitimate authority) not only to express value and aesthetic judgments but also to express an ethical and aesthetic judgment that supports the practice socially. What is negotiated and contested within a practice, and among practitioners, is not the effectiveness 
or the efficiency of the practice (not only), but the vision of the world (normative and aesthetic) that sustains a collective mode of doing. Practitioners have an emotional, aesthetic, and ethical attachment to the practices that they support and reproduce. Practices and disputes about them among practitioners express, create, and celebrate a taste of the practice (Gherardi, 2012a) within the community of practitioners.

\section{A practice is a collective knowledgeable doing}

A working practice is not only a set of activities performed by knowledgeable practitioners, but it is also a common way of doing and knowing what to do. Practitioners' sense of what is a practice is a felt sense of what is appropriate, what should be done next, when to act, and when something is correct or incorrect, effective or not, good and beautiful, or not. Knowing is something people do together (Gergen, 1985) and it is done in every mundane activity, in organizations when people work together. From this perspective, we may start to study knowing empirically as a situated activity.

As much in everyday life as in work organizations, people and groups create knowledge by negotiating the meanings of words, actions, situations, and material artifacts. They all participate in and contribute to a world that is socially and culturally structured and constantly reconstituted by the activities of all those who belong to it. Knowledge is not what resides in a person's head or in books or in data banks. To know is to be capable of participating with the requisite competence in the complex web of relationships among people, material artifacts, and activities. On this definition, it follows that knowing in practice is always a practical accomplishment, and practicing a practice implies knowing how to go on. Therefore, one of the most important directions taken by empirical studies that relay on post-human practice theory is the study of the practical organization of knowledge, in the form of methods of seeing, reasoning, and acting in association with human and non-human elements. This signifies that knowing can be studied as a social process, human and material, aesthetic as well as emotive and ethical, and that knowledge is embedded in practice, as the domain where doing and knowing are one and the same.

\section{Situated knowing is affective-corporeal knowing}

A central theme in the study of working practices has been the knowledge hidden within practices: that is, pre-verbal, affective, corporeal, and nonrational knowledge. The aesthetic analysis of organizational life (Strati, 1999) is directed to understanding the relations among aesthetics, emotions, and affectivity, and it focuses on the problematic nature of the knowledge deriving from the senses. Polanyi (1958) pointed out that, in everyday practice, we are often aware of being able to do something but unable to describe analytically how we do it, to explain it scientifically, and thereby turn it into explicit rather than implicit and entirely personal knowledge. Sensible knowledge has precisely this characteristic: it evades logical-analytical description and scientific formalization and is better expressed evocatively and metaphorically.

In fact, 'sensible knowledge concerns what is perceived through the senses, judged through the senses, and produced and reproduced through the senses. It resides in the 
visual, the auditory, the olfactory, the gustatory, the touchable and in the sensitive-aesthetic judgments. It generates dialectical relations with action and close relations with the emotions of organizational actors' (Strati, 2007, p. 62). A crucial point in regard to sensible knowledge is made by Merleau-Ponty (1945). He takes accounts of the subject's intimate, personal, and corporeal relation with the experience of the world and does not restrict such knowledge to the mere direct, physical, and objectively observable relation.

Practical knowledge is acquired also at the sensory and aesthetic levels: 'knowing how' is inherently also 'feeling and sensing how'. The bodily abilities are developed by the individual, but the community elaborates and transmits the codes of appropriateness for a disciplined body and the criteria of aesthetic evaluation of work performance (the aesthetic pleasure produced by a job well done). Developing a sense for a certain way of practising relies on ineffable subtleties derived mainly from repeated exposure to clues and sensory experiences provided by the unfolding activity, as well as on the linguistic productions that take place during the activity. Moreover, the material body - the body that works - assumes shape and location within the set of practices that constitute the work setting. The knowledge acquired via the five senses is aesthetic, not mental. It often forms the basis for specific competences. Craft trades required trained bodies - ones, that is, which have incorporated an expertise. It is through the body that 'an eye' (or 'an ear' or 'a nose') for something is acquired, so that aesthetic knowledge (Strati, 2003) also comprises the ability to develop a professional 'vision' in the broad sense. Practical knowledge is embedded in corporeality in the twofold sense that the body is the sources of aesthetic knowledge, and that knowing how to know through the body (and therefore knowing how to develop a body disciplined in accordance with the requirements implicit in practices) is part of the professional culture (Green \& Hopwood, 2015).

One of the main concerns of a practice-based approach is to understand this kind of 'don't-know-what' (Strati, 2007), that is, how people, while they are absorbed in the practice at hand are able to discern the situated logic that connects together the inner actions, and on this basis prefigure the performance of the practice as an ongoing achievement. Knowing in practice is therefore a contingent ordering, the effect of the ability of practitioners to find their bearings using the context as a resource, and articulate the matter of the world (objects, artifacts, technologies) within a form.

Practice-based studies, in a post-human epistemology, stress how knowing is embodied and pre-verbal and in doing so link the turn to practice with the turn to affect. In both cases, the point they wish to make is that there is much more beyond discourse and beyond mind.

\section{Relations in practice as sociomaterial entanglements}

The concept of sociomateriality directs attention to working practices as loci of the entangled forming of meaning and matter. Practices are seeing as sites of knowing, working, and organizing (Nicolini, 2011; Schatzki, 2005). Consequently, a key question becomes the following: how are all the elements - material and semiotic - which make up a practice assembled, held together, and interrelated?

One answer comes from practice-based studies on the practical organization of knowledge taking the form of situated methods of seeing, reasoning, and acting in an association of human and non-human elements. 
Not only do subject and object define each other within a context of interaction, but also the relationship between the material and the discursive comes about as a single phenomenon in which not only is materiality social - as social studies on technology have shown (Law, 1994) - but the process of meaning-making encompasses material semiosis. In Law's (1994, p. 24) definition, relational materialism is a process of 'ordering [that] has to do both with humans and non-humans' (emphasis in the original). The epistemology of practice is a post-human project in that it seeks to decenter the human subject and reconfigure the concept of agency within sociomaterial practices.

The term 'sociomateriality' has come into use after removal of the hyphen between the two terms (Orlikoswki, 2007). And the term 'intra-action', coined by Barad (2003; 2007) to locate the relationship of mutual determination between subject and object, has also entered the lexicon of organization studies (Iedema, 2007; Nyberg, 2009) in relation to practice as epistemology. The purpose of these concepts is to emphasize that 'materiality is integral to organizing, positing that the social and the material are constitutively entangled (italics in the original) in everyday life' (Orlikowski, 2007, p. 1437). A position of constitutive entanglement privileges neither humans nor technologies, neither knowing nor doing; nor does it link them in a form of mutual interdependence.

In other words, it is in the historically situated context of a practice that the knowing subject, the object of knowledge, and sociomateriality are involved in the processes of 'becoming' through which their identities are materially negotiated and (re)confirmed (Chia, 2003, p. 106). This focus on becoming thus conceives of organizations - and organizational practice as well - 'not as an ontological stable object, but rather something that exists only in its duration' (Clegg et al., 2005, p. 159).

The epistemology of practice makes it possible to articulate the dynamic that occurs between the becoming of a practice as a socially sustained mode of action in a given context and the 'given' sociomaterial context in which it develops. Practice is situated between the given and the emergent as an element in the sociomaterial ordering.

\section{The situational territory of practicing}

When a practice becomes such - that is, it has become recurrent and coalesced into habits - the context of the practice is very probably an equipped context in which the main handholds for regular performance of the practice are known; they have been made familiar by repetition of the practice; they have been equipped so as to elicit their habitual use. Then, artifacts, tools, objects, and technologies come into play, and therefore, materiality (Svabo, 2009) anchors relations and meanings and 'suggests actions'. Numerous concepts have been proposed to express this interpretative shift from the context as a 'container' - more or less neutral and indifferent to the actions that develop within it - to the context as a 'resource' (Lave's 'arena' and 'setting'). For example, the idea of 'in-strumentation' (Rabardel, 1995) that stresses how instruments are not such in themselves but become instrumental in the relation with the action that they serve; the affordance of materiality (Gibson 1979) that suggests its use to support a utilization; the intra-action of Barad (2003) that coarticulates meanings and materialities; the concept of 'jigging' (Kirsh, 1995, p. 37) as a way to prepare and structure the environment. The more completely prepared the environment is, the easier it becomes for practitioners to accomplish their activities. 
In other words, the recursiveness of practices establishes a relationship of coproduction with the environment in which not only are the handholds for action discovered in the course of that action, but also delegated to these handholds is the execution of certain operations of the same practice or certain functions, such as remembering (Grosjean \& Bonneville, 2009), where helping not to forget is anchored in the materiality of signaling artifacts and technologies. Embedded in the theme of the equipped environment that anchors activities by suggesting to practitioners 'what next' in performance of the practice is the idea of improvisational choreography proposed by Whalen et al. (2002) when describing the arrangement of the objects and the gestures, as well as the body, of a call center operator. Just as choreography is a matter of space and time - and a somewhat extemporaneous composition in this case - so the operator conveys to the caller that the latter's request is being handled fluidly - without impeding the interaction and therefore with competence, by skillful management of an equipped environment and with a cadence that does not leave gaps in the interaction (Whalen et al., 2002, p. 245-253). The locally organized, improvisational choreography can be describe as a kind of 'performance' (Goffman, 1959), which is shared by sales representatives, which is methodical in character, and which is grounded in the exigencies of their practices.

\section{Practice innovation as a continuous process}

What is meant by innovation as a continuous process based on practices can be conveyed by the following quotation from Weick (1979, p. 247):

'if an organization updates itself on a daily basis then it's possible for that organization to maintain a close fit with its surroundings' (italics in original).

In other words, innovation is not just the result of deliberate activities that introduce discontinuities in working practices; it is also produced on a daily basis by all those who engage in the working practices of their organizational life. To innovate working practices 'from outside' and with a top-down approach has proved more and more difficult, especially once the climate of reciprocal trust between social partners has been eroded and the role of trade unions has declined. I shall not enter into a detailed discussion of how the pervasiveness of neoliberalism has affected labor market policies and work organization. What I wish to suggest is that nevertheless the general degradation of the quality of working life, practitioners, and professionals continue to have a certain attachment to the object of work and they care about their way of working. Working practices therefore have an internal dynamic of continuous change put in motion by practitioners who are affected by macro-dynamics of work organization, but also wish to affect what they do and the meaning of work in their life.

Practice-based studies are born for illustrating the gap between formal description and prescription of work design and the situated working practices, in order to bring into focus the canonical and non-canonical practices of a group of people who work, and as they do so develop, conserve, re-elaborate, transmit, and innovate the knowledge necessary for what they do. Fine-grained descriptions of working practices, most of them coming from ethnographic studies of work, have supported the participative 
development of information systems and various tools supporting human work (CecezKecmanovic et al., 2014).

Situated practices constitute a particular locus for continuous and incremental innovation in so far, as they enable its practitioners to insert spaces among canonical (i.e., predetermined) practices in which to develop non-canonical views, that is, ones richer and more flexible and subject to constant change. Within these spaces, a situated knowledge develops and is preserved that becomes a collective asset and the source of idiosyncratic power. However, it should be borne in mind that, besides the idea of the constant improvement and change of practices by members variously motivated to innovate, a community may also be a barrier against learning and innovation (Amin \& Cohendet, 2004; Tagliaventi \& Mattarelli, 2006).

The assumptions on which innovation may be considered as a continuous process situated in work practices are the following:

- knowledge is produced through participation in a set of practices;

- participation in work practices leads to the development of a collective identity;

- participation in a practice entails legitimate participation in the negotiation of the meanings of those practices and the ethical and aesthetic criteria for evaluation of practice. What constitutes a good (beautiful) practice or a bad (ugly) practice is subject to continuous discussion and negotiation among the participants;

- innovation as a continuous process is produced through continuous refinement of practices by those who have created them.

From these assumptions arises a view of knowledge not as a simple 'object' that can be transferred from person to person or from one organization to another; on the contrary, knowing is a practical activity in itself (Gherardi, 2012b). Practice is therefore the locus of production of knowledge and practicing is a constant source of innovating practices. From this point of view, therefore, continuous innovation is the specific endogenous dynamic of practice change; it is a constant process of practice refinement. The continuous refinement of practices can be better understood in light of the concept of practical reflexivity (Cunliffe \& Easterby-Smith, 2004) activated by participation in a practice. In fact, the collective process of reflecting on taken for granted forms of practicing and bringing them at a discursive level open new possibilities for action. At the beginning of the article, I positioned the heuristic value of practice within an ecological model of interpretation, a model in which no element (either human or nonhuman) has ontological priority over the others. Hence, action does not start from the actors and their intentionality; rather, it 'takes place' in the sociomaterial relations that connect those elements together. It is on this assumption that practice can be interpreted as the locus of working, organizing, and innovating (Nicolini, 2013).

A further specification is necessary to understand the dynamic of practice refinement as a continuous process of innovation. Practice, in fact, should be considered not only as an assemblage of activities but also as a social relationship between the practice and those who create and support it. When work practices are viewed from the standpoint of the practitioners, that is, 'from within' with the eyes of the practitioners, what is of interest to the researcher is the intellectual, passionate, ethical, and aesthetic attachment that ties subjects to objects, technologies, the places of practices, and other practitioners.

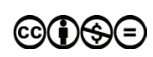


The attachment to the object of practice - be it of love or hate - is what makes practices socially sustained by judgments relating not only to utility but also to ethics and aesthetics as well. The relationship with the object exemplifies a relation in which the practitioner is an 'amateur'1 - somebody who cares about the object of his/her work/ profession - and s/he is indeed active, that is, deploys a set of situated practices in order to use and enjoy the object of his/her passion individually and collectively, but s/he is also passive, in that s/he deliberately, and in a 'cultivated' manner, abandons him/herself to the effect of the object in so far, as s/he predisposes the material conditions for the enjoyment of what is collectively done, and socially shares this passion within a community of amateurs (Gherardi et al., 2007).

The problem of the attachment that ties the practitioner to his/her practice and its object, as well as to his/her identity as a practitioner and to other practitioners is a problem of a passionate and pleasurable or painful relation both shared and collectively elaborated. Attachment is not only the relation with the object and the deliberate production of the desired effect, but it is also the effect of the collective formation of the taste (taste-making) at the moment when the aesthetic judgments supporting the practice are formed. Taste-making has been defined as the process of giving voice to passion and negotiating aesthetic criteria that support what constitutes 'a good practice' or 'a sloppy one' and 'a beautiful practice' or 'an ugly one' within a community of practitioners (Gherardi, 2009). It is formed within situated discursive practices. The aesthetic judgment is made by being said - and therefore, it presupposes the collective elaboration and mastery of a vocabulary for saying - and it is said by being made.

We can draw an interpretative scheme for a sociology of working practices that enables us to consider practitioners in a wider way: not for what they do and their competence in doing, but also for their attachment to the object of their practices, as 'amateurs' of what they do. We shall thus see emerging in the practitioner-amateur the figure (and the lexicon) of the critic, s/he who formulates aesthetic judgments on practice.

This dynamic that enables the reproduction of practices as a constant process of refinement has been aptly defined by Béguin and Clot (2004) as 'répétitions sans répétitions' (repetition without repetitions) or by Gomart and Hennion (1999, p. 238) as 'hyperesthesia', a particularly developed competence to perceive, practise, combine, and elaborate the object of the practice. Also in Heidegger (1927) repetition is not repetitive, it is a kind of redundancy that improve practices.

The continuous innovation of practice therefore springs from the constant elaboration of the canons with which the community appraises and judges the object of the practice. Dissent is therefore an element that drives the constant endeavor to refine the methods and meaning of the practice for those who derive identity from it. The pleasure of practicing and sharing that pleasure, passion as an attachment to the object of the practice, and mediation with the tools of the practice are further elements that sustain reproduction of the practice and that make it possible to answer the questions as to why a practice continues to be practiced and how it changes by being practiced.

The attachment of practitioners to the object of practice is constructed in the moment and in the space of the practicing, in intuitive knowledge. Judgments on the correctness or otherwise of the practice are not external to its practicing, but are formed within the action and are not only sustained by practice but constitute it. Internal appraisal of performances, conducted from 'within' the community, fashions the vocabulary of taste 
necessary to refine practices while skillfully repeating them. And, within repetition, to share the pleasure of doing is also to share the pleasure of being.

The analytical elements that enable empirical investigation of the innovation process as a continuous refinement of practice can be summarized thus:

1. the mobilization of sensible knowledge (the bodily ability to perceive and to taste), the sharing of a vocabulary for appraising the object, and the object in place. Developing a vocabulary of appraisal enables the community of practitioners to communicate about sensible experiences, to draw distinctions of taste, and to spread them through the community;

2. the mutual constitution of the subject and the object within practice. Taste-making crafts identities and knowledgeable communities at the same time, and sharing an aesthetic provides the feeling of belonging to a specific community within a community;

3. the continuous refinement of practices and their historicity in relation to past practices and their continuation in future ones accounts for a change and persistence in practices. We can see in the formation of taste, both its dependence on aesthetic judgments made in the past and embedded in current practice, and the aesthetic knowing that, through repeated attempts, constantly refines the practice.

\section{Conclusion}

What working life studies and practice-based studies have in common is 'work', but what do people do when they work? When they work is that all they do? It is this perspective that has been resumed by the practice-based studies that continue the phenomenological and ethnomethodological tradition, and the study of situated working practices also responds to a need for better understanding of the difference between prescribed work and real work (Licoppe, 2008), a problem long present in the European sociology of work. In this intellectual tradition, the turn to practice in the beginning of 2000 signed the confluence between working, knowing, and innovating in a single theoretical construct: practice.

The study of work in situation is not only descriptive in its purpose, but it is also intended to yield practical outcomes. Indeed, it is precisely this applicative intent that has induced rediscovery of the ethnography of work, and other qualitative methodologies, which have led to revaluation of the sociologist's role in interpreting the relation between all the elements - human and non-human - in working practices.

The methodological assumption is that, in order to design any aspect of a work setting, it is necessary to understand the relationship between this aspect and the set of activities and technologies of which it is only one part. It is also necessary to bear in mind that the products of any professional design (objects, technologies, environments, and so on) have been conceived and produced on the basis of a partial and situated projection of the circumstances in which they will be used. Consequently, such products must not be taken as definitive, but rather as starting points for the development of artifacts-in-use, which will be inevitably adapted or changed so that they can be introduced into the work environment. This applies to technologies and their problematic introduction into workgroups and spaces, as well as to every object of day-to-day use, which is transformed in its use.

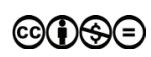


Therefore, in general terms, when the theme of working practices is related to the design of technologies and collaborative work settings, it is assumed that the requirements for their design/production are discovered and/or created through the contingencies of their everyday use, and through the solutions that the participants invent to deal with problems and ambiguities. When the theme of working practices is related to practitioners' exploration of their practices and their practical reflexivity for innovating or reaffirming them, what is assumed is that practitioners may be empowered through questioning their habitual way of seeing work and acting in the world.

\section{References}

Amin, A. \& Cohendet, P. (2004) Architectures of Knowledge. Firms, Capabilities, and Communities. Oxford: Oxford University Press.

Barad, K. (2003) 'Posthumanist Performativity: Toward an Understanding of How Matter Comes to Matter', Signs, 28(3): 801-831.

Barad, K. (2007) Meeting the University Halfway: Quantum Physics and the Entanglement of Matter and Meaning. Durham: Duke University Press.

Béguin, P. \& Clot, Y. (2004) 'L'action Située dans le Development de l'Activité' (Situated action in activity development), @ctivites, 1(2): 27-49.

Braidotti, R. (2013) The posthuman. Cambridge: Polity Press.

Cecez-Kecmanovic, D., Galliers, R.D., and Henfridsson, O. (2014) 'The sociomateriality of information systems: current status, future directions'. MIS Quarterly 38(3): 809-830

Chia, R. (2003) 'Ontology: Organization as "World-making”, in Westwood R and Clegg S. (eds.) Debating Organization: Point-counter-point in Organization Studies. Oxford: Blackwell Publishing, 98-113.

Clegg, S., Kornberger, M. \& Rhodes, C. (2005) 'Learning/Becoming/Organizing', Organization, 12(2): 147-67.

Clough, P.T. (2009) 'The New Empiricism: Affect and Sociological Method', European Journal of Social Theory, 12(1): 43-61.

Cook, S.D. \& Brown, J.S. (1999) 'Bridging Epistemologies: The Generative Dance between Organizational Knowledge and Organizational Knowing', Organization Science, 10(4): 381-400.

Cunliffe, A.L. and Easterby-Smith, M. (2004) 'From reflection to practical reflexivity: Experiential

learning as lived experience', in Reynolds. M. and Vince, R. (eds) Organizing Reflection. Aldershot: Ashgate, 30-46.

Edwards, R. \& Fenwick, T. (2014) 'Critique and politics: a sociomaterialist intervention', Educational Philosophy and Theory, online first: DOI:10.1080/00131857.2014.930681

Eikeland, O. \& Nicolini, D. (2011) 'Introduction. Turning Practically: Broadening the Horizon' Journal of Organizational Change Management, 24(2): 164-174.

Elkjær, B. (2003) 'Organisational Learning with a Pragmatic Slant', International Journal of Lifelong Education, 22(5): 481-494.

Garfinkel, H. (1967) Studies in Ethnomethodology. Englewood Cliffs, NJ: Prentice Hall.

Gergen, K. (1985) 'The Social Constructionist Movement in Moderns Psychology', American Psychologist, March, 266-275.

Gherardi, S. (2009) 'Practice? It's a Matter of Taste! Management Learning', 40(5): 535-550.

Gherardi, S. (2011) 'Organizational Learning: The Sociology of Practice', in Easterby-Smith M. \& Lyles, M. (eds.) The Blackwell Handbook of Organizational Learning and Knowledge Management, Malden, Oxford, Melbourne, Berlin: Blackwell Publishing, 43-65. 
Gherardi, S. (2012a) How to conduct a practice-based study: problems and methods, Cheltenham, Gloss: Edward Elgar.

Gherardi, S. (2012b) 'Why Do Practices Change and Why Do They Persist? Models of Explanations', in Hager, P., Lee, A. \& Reich, A. (eds.) Practice, Learning and Change: Practice Theory Perspectives on Professional Learning, New York: Springer International, 217-231.

Gherardi, S., Nicolini, D., and Strati, A. (2007) 'The Passion for Knowing'. Organization 14/3: 309-323.

Gibson, J.G. (1979) The Ecological Approach to Visual Perception. Boston, MA: Houghton Mifflin.

Goffman, E. (1959) The Presentation of Self in Everyday Life. Garden City, NY: Doubleday.

Gomart, E. \& Hennion, A. (1999) 'A Sociology of Attachment: Music, Amateurs, Drug Users', in Law, J. \& Hassard, J. (eds.) Actor Network and After. Oxford: Blackwell Publishers, 220-247.

Green, B. \& Hopwood, N. (2015) The Body in Professional Practice, Learning and Education. London: Springer.

Grosjean, S. \& Bonneville, L. (2009) 'Saisir le Processus de Remémoration Organisationnelles des Actants Humain et Non Humain au Cœur du Processus' (to evaluate the process of organizational remebering in human and non- human actants at the heart of the process), Revue d'Anthropologie des Connaissance, 3(2): 317-47.

Heidegger, M. (1927) Sein und Zeit. (Engl translation Being and Time (1996) by J. Stambaugh), Albany: State University of New York Press.

Iedema, R. (2007) 'On the Multi-Modality, Materiality and Contingency of Organizational Discourse', Organization Studies, 28(6): 931-946.

Kirsh, D. (1995) 'The Intelligent Use of Space', Artificial Intelligence, 73(1-2): 31-68.

Langley, A. and Tsoukas, H. (2010) 'Introducing Perspectives on process organization studies', in T. Hernes \& S. Maitlis (eds) Process, Sensemaking, and Organization Oxford: Oxford University Press, 1-26.

Latour, B. (2005) Reassembling the Social. Oxford: Oxford University Press.

Law, J. (1994) Organizing Modernity. Blackwell: Oxford.

Licoppe, C. (2008) 'Dans le 'Carré de l'Activite': Perspectives Internationales sur le Travail et l'Activité' (within the 'frame of activity'. International Perspectives on work and activity), Sociologie du Travail, 50(3): 287-302.

Merleau-Ponty, M. (1945) Fénomenologie de la Perception (Phenomenology of Perception). Paris: Edition Gallimard.

Miettinen, R. Samra-Fredericks, D. \& Yanow, D. (2009) 'Re-turn to Practice: An Introductory Essay', Organization Studies, 30(12): 1309-1327.

Nicolini, D. (2011) 'Practice as the Site of Knowing. Insights from the Field of Telemedicine', Organization Science, 22: 602-620.

Nicolini, D. (2013) Practice Theory, Work, and Organization. Oxford: Oxford University Press.

Nyberg, D. (2009) 'Computers, Customer Service Operatives and Cyborgs: Intra-actions in Call Centers', Organization Studies, 30(11): 1181-99.

Orlikowski, W.J. (2007) 'Sociomaterial Practices: Exploring Technology at Work', Organization Studies, (28)9: 1435-48.

Polanyi, M. (1958) Personal Knowledge. Towards a Post-Critical Philosophy. Chicago: University of Chicago Press.

Rabardel, P. (1995) Les Hommes et les Techniques, une Approche Cognitive des Instruments Contemporains. (Persons and technics, a cognitive approach to contemporary instruments)Paris: Armand Colin. 
Schatzki, T.R. (2005) 'The Sites of Organizations', Organization Studies, 26(3): 465-84.

Strati, A. (1999) Organization and Aesthetics. London: Sage.

Strati, A. (2003) 'Knowing in Practice: Aesthetic Understanding and Tacit Knowledge', in Nicolini, D., Gherardi, S. \& Yanow, D. (eds.) Knowing in Organizations. Armonk, NY: M.E. Sharpe, 53-75.

Strati, A. (2007) 'Sensible Knowledge and Practice-Based Learning', Management Learning, 38(1): 61-77.

Svabo, C. (2009) 'Materiality in a Practice-Based Approach', The Learning Organization, special issue on Knowing and Learning in Practice-Based Studies, 16(5): 360-370.

Tagliaventi, M. R. \& Mattarelli, E. (2006) 'The Role of Networks of Practice, Value Sharing, and Operational Proximity in Knowledge Flows between Professional Groups', Human Relations, 59(3): 291-319.

Weick, K. E. (1979) The Social Psychology of Organizing, 2 ${ }^{\text {nd }}$ edition. New York: McGrawHill.

Whalen, J., Whalen, M. \& Henderson, K. (2002) 'Improvisational Choreography in Teleservice Work', British Journal of Sociology, 53: 239-58.

\section{End note}

1 The word 'amateur' has a Latin root: amare that literally means to love. Amateur is somebody who practices as dabbler (i.e., non-professional, not for duty) and somebody who practices for the love of what s/he does. An amateur of classical music is therefore not a professional, but common sense holds that a soprano is a lover of classical music. I therefore proposed (Gherardi, 2009) to analyze practitioners as 'amateurs' in order to explore the collective dimension of the attachment to the work object that sustains working practices and makes them change over time. Even though talking of practitioners as 'amateurs' may seem a contradiction in terms, it signals that work has been stripped of the passionate element and subjected to a predominantly instrumental logic (Gherardi et al., 2007). 